\title{
Recombinant Human Papillomavirus Bivalent Vaccine
}

National Cancer Institute

\section{Source}

National Cancer Institute. Recombinant Human Papillomavirus Bivalent Vaccine. NCI

Thesaurus. Code C48395.

A recombinant, bivalent, human papillomavirus (HPV) vaccine, containing virus-like particles for HPV types 16 and 18 linked to the adjuvant ASO4, with potential immunoprotective and antineoplastic properties. Upon administration, HPV 16/18 L1 virus-like particle/ASO4 vaccine may generate humoral and cellular immunity against HPV types-16 and -18 antigens, thereby preventing cervical infection upon exposure to HPV types 16 and 18. In addition, this agent may stimulate an antitumoral cellular immune response against cervical cancer associated with HPV infection. 